\title{
Gut content analysis of indian mackerel (rastrelliger kanagurta)
}

\begin{abstract}
Analysis of gut content is widely used to ascertain the food and feeding habit of fish species. Diets of fishes represent an integration of many important ecological components that included behavior, condition, habitat use, energy intake and inter/intra specific interactions. The food and feeding of the Indian mackerel Rastrelliger kanagurta ${ }^{1}$ was studied based on 42 fishes ranging in size from 13 to $25 \mathrm{~cm}$ Total Length (TL), collected by purse seiner during the summer period (February to April), the period in which the fish is available along the Massawa Coast. The methodologies followed in this study are Occurrence method for recording the stomach contents; Gravimetric method to evaluate the net weight of individuals per stomach in each food category ${ }^{2,3}$ Volumetric (Displacement) method used for estimation of various food items ${ }^{4}$ and also Index of Preponderance used to evaluate the relative value of different organisms in the $\operatorname{diet}^{5}$ There was a preponderance of empty stomachs is noticed. The dominant food item observed was Copepod. The fish (Bregmaceros sp.), Sand and fish scale also formed part of the stomach content.
\end{abstract}

Volume 3 Issue I - 2015

\author{
Selvam R Nath, Teklehaimanot Beraki, Awet \\ Abraha, Kiflom Abraham, Yonas Berhane \\ Department of Marine Biology and Fisheries, College of Marine \\ Science and Technology, India
}

Correspondence: Selvam R Nath, Department of Marine Biology and Fisheries, College of Marine Science and Technology, TC 36/39I-4, Lalith, Mookambika Lane, Vallakkadavu PO, Trivadandrum-8, Kerala, India, Tel 9946003161, Email selvamrnath@gmail.com

Received: September 03, 2015 | Published: October 28, 2015

Keywords: Fishes, Total length, Preponderance, Rastrelliger kanagurta, Eritrean

Abbreviations: TL, Total Length; EBFM, Ecosystem Based Fisheries Management; FL, Fork Length; SL, Standard Length; IL, Intestinal Length; cm, Centimeters; gm, Gram; RI, Ranking Index; PFO, Percentage Frequency of Occurrence

\section{Introduction}

Analysis of gut content is widely used to ascertain the food and feeding habit of fish species. Diets of fishes represent an integration of many important ecological components that included behavior, condition, habitat use, energy intake and inter/intra specific interactions. Accurate description of diets and feeding habits provides the basis for understanding the trophic interactions in aquatic food webs. ${ }^{6}$ Investigation on the food and feeding habits will throw more light on the migratory and shoaling habits of pelagic fish species and it is particularly important for a species of high commercial value such as the mackerel. The feeding habits of most marine fishes are roughly grouped in to the following three major trophic categories: Carnivorous, Omnivorous and Herbivorous. ${ }^{7}$ Most studies on fish diets rely on examination of stomach content to quantify prey abundance usually to a coarse taxonomic resolution where the main aim of the study is ecology-based..$^{8-11}$ The diet of fishes changes with a number of factors which are extrinsic (biotope, region) or intrinsic (species, size, behavior) and thus information on diet of fishes is important to understand the basic functioning of fish assemblages which are important for developing Ecosystem Based Fisheries Management (EBFM) models. ${ }^{12,13}$ Studying feeding habit of fishes does have great importance both in Fisheries and Aquaculture. In Fisheries it provides information on distribution pattern and the feeding ground of both local and regional and also has direct implication for fishing gear such as long line and fish trap which use as a bait. In Aquaculture the knowledge of food item requires for the larvae in order to provide different live food at different life stages. Qasim ${ }^{14}$ while providing a critical appraisal of the existing knowledge of food and feeding habits of marine fishes in Indian waters, emphasized the importance of chemical analyses of food of fishes as it is of crucial importance in understanding dynamics of energy and its channeling to various trophic levels.
The general features for Rastrelliger kanagurta ${ }^{1}$ dorsal fins wellseparated, the first triangular with 8 to 11 spines; the second dorsal and anal fins with 12 rays, followed by five fin lets; pectoral fins very short with 19 to 20 rays; gill rakers very long, visible when mouth is open, 30 to 46 on lower limb of first arch; front and hind margins of eye covered by adipose eyelid; scales behind head and around pectoral fins larger and more conspicuous than those covering rest of body, but no well-developed corselet; generally silver; narrow dark to golden stripes on upper part of the body; usually a double longitudinal raw of small dusky spots on upper back; a prominent black spot on body under lower margin of pectoral fin; dorsal fins yellowish with black tips; caudal and pectoral fin often yellowish. The Indian mackerel, Rastrelliger kanagurta ${ }^{1}$ is a pelagic shoaling fish that forms commercial fisheries along the coasts of the countries bordering the Red Sea, Oman Sea, Arabian Gulf, Pakistan, India, Sri Lanka, Bangladesh, Myanmar, Thailand and Malaysia. ${ }^{15}$ It is also important component of Eritrean fisheries since 1960's for human consumption and as a source of fish meal by employing Purse seiner. During the summer period, February to April, Indian Mackerel is most abundant in the Eritrean Red Sea Coast. Even though in most part of the world a lot of studies were conducted in the food and feeding behavior of Indian Mackerel, in Eritrean Red Sea this is a pioneer attempt to this study. Since the availability of the fish in Eritrean Red Sea is very short period, is a major constrain for the prolonged study round the year. Taking into consideration of the fisheries and the role of Mackerel in the food web in the ecosystem, the present study has been carried out to get a base line data on the feeding behavior of the Indian Mackerel in Eritrean Red Sea.

\section{Materials and methods}

Sampling of 42 individual Indian Mackerel Rastrelliger kanagurta $^{1}$ fishes ranging in size from $13 \mathrm{~cm}$ to $25 \mathrm{~cm}$ of Total Length (TL), collected by purse seiner during the summer period (February to April), the period in which the fish is available along the Eritrean Red Sea Coast. According to Collette \& Nauen ${ }^{15} \&$ Fish base (www. fishbase.org) the length at first maturity ranges from $20 \mathrm{~cm}$ to 25 $\mathrm{cm}$. Therefore the sample consists of both juvenile and adult forms 
together. The specimens were preserved in ice until it reaches to the laboratory. The Morphometric measurements of each individual samples were taken before dissection: Total Length (TL), Fork Length (FL), Standard Length (SL) and Intestinal Length (IL). Length measurements were made to the nearest centimeters $(\mathrm{cm})$ whiles the weight measurement to the nearest gram (gm). The fish samples were dissected and stomach content removed and the weight of the stomach content measured. The stomach contents were preserved in $4 \%$ formalin solution for further analysis.

The weights of each food item were weighed with sensitive digital balance. The stomach content were placed in petridish and sorted in to different groups of food items. For each stomach the volume and weight of preserved individuals in each prey taxon were recorded. Prey weights were scaled up to account for digestion by reference to a range of size of undigested prey specimen. Identification of prey was done by visually and by using microscope. And pictures were taken by spreading the prey items in white paper. Stomach content in an advanced state of digestion was not used for the analysis.

Data analysis was followed by Hyslope, 1980. For each food item the following parameters were calculated. Occurrence method Possibly the simplest way of recording data gleaned from the stomach content is to record the number of stomach containing one or more individuals of each food category, this number may then be expressed as a percentage of all stomachs ${ }^{2}$ or all those containing food. Gravimetric method, the net weight of individuals per stomach in each food category is recorded for all stomachs and the total is expressed as a percentage of the total net weight of all food categories. Displacement method (volumetric) method as suggested by Pillay ${ }^{4}$ was employed for the estimation of various food items. An index of relative importance formed the basis of assessment of prey importance. The relative value of different organisms in the diet was evaluated by the Index of preponderance. ${ }^{5}$ Individual stomach fullness degree was estimated according to the subjective scale, its ranges from (empty) to $3 / 4$ full. Ranking Index (RI) was calculated by multiplying mean volumetric percentage and percentage frequency of occurrence. Pleilou measure eveness (E) and Shannon index of diversity were calculated

$$
\begin{aligned}
& \mathrm{H}^{\prime}=-\Sigma \mathrm{pi}(\ln (\mathrm{pi})) \ldots \ldots \ldots \ldots \ldots \ldots \text { Shannon diversity } \\
& \mathrm{E}=\mathrm{H} /(\ln \mathrm{N}) \ldots \ldots \ldots \ldots \ldots \ldots . \ldots . \ldots \ldots \text { Pleilou measure eveness }
\end{aligned}
$$

Where $\mathrm{Pi}$ is the proportion by volume of a particular prey category; $\mathrm{N}$ is prey categories. The Shannon index increase according to the number and proportion of prey identified from the diet. It varies from zero to $\log \mathrm{N}$. $\mathrm{N}$ is number of prey type. In other words the lower this index, the more specialized the diet and vice versa. Eveness, E, was calculated to measure the degree to which the various prey types are equally represented in the diet. It varies from 0 to 1 .

\section{Results and discussion}

Food and feeding of Indian mackerel were investigated based on the examination of stomach contents of 42 individuals. Since no one method of stomach content analysis is satisfactory for describing the importance of any one food item, a multi method procedure was adopted, in order to minimize bias typical of each method by Pillay. ${ }^{4}$ Six $(14.2 \%)$ of 42 fishes examined had empty stomach. The food composition is summarized in Table 1. From this study the food item of R. kanagurta were categorized into four major groups. The stomach content were consisted as first rank crustacea, second fish and sand and scale interchange the third position in volumetric and gravimetric.
From the entire food item consumed by Indian mackerel crustaceans made the major part of the total content of the stomach by volume and by weight. The crustacea main components were copepods. ${ }^{16}$ We take a picture that the appearance of sand substance was grainy texture and for copepods it was brownish. The pictures are presented in the Figure 1 and Figure 2. The Percentage Frequency of Occurrence (PFO) of these crustaceans was found $97.2 \%$, PFO of fish $66.7 \%$; PFO of sand was $38.8 \%$ and fish scale $30.6 \%$. Diet composition in relation to size groups; group size 16-18 cm (total length) which are smallest size group has found with the highest intestinal length averagely $67 \mathrm{~cm}$ so possibly their prey preference could be plant matter or detritus. Size group 18-21 cm had intestinal length averagely $56 \mathrm{~cm}$; this indicates that the larger ones are carnivores (Table $2 \& 3$ ). An index of relative importance of prey or index of preponderance shows as those crustaceans ranked first which is about $74 \%$ (Figure 3).

Table I Volumetrically crustaceans accounted $60.48 \%$, fish (Bregmaceros sp.) $22.42 \%$, sand $8.68 \%$, and fish scale $8.41 \%$. Gravimetrically crustaceans constituted $51.15 \%$, fish $30.35 \%$, sand II.34\% and scale $7.15 \%$

\begin{tabular}{lll}
\hline Food item & Volumetric \% & Gravimetric \% \\
\hline Fish & 22.42 & 30.35 \\
Crustaceans & 60.48 & 51.15 \\
Sand & 8.68 & 11.34 \\
Fish Scale & 8.41 & 7.15 \\
\hline
\end{tabular}

Table 2 Mean Percentage by volume and other indices of the food item group

\begin{tabular}{llll}
\hline Food item & $\begin{array}{l}\text { Mean } \\
\text { volumetric \% }\end{array}$ & $\begin{array}{l}\text { (\%) Frequency } \\
\text { occurrence }\end{array}$ & $\begin{array}{l}\text { Ranking } \\
\text { index }\end{array}$ \\
\hline Fish & 22.42 & 66.7 & 1495.4 \\
Crustaceans & 60.48 & 97.2 & 5880.6 \\
Sand & 8.6 & 38.8 & 333.68 \\
Fish Scale & 8.4 & 30.6 & 257.04 \\
\hline
\end{tabular}

Table 3 Mean Percentage by weight and other indices of the food item group

\begin{tabular}{llll}
\hline Food item & $\begin{array}{l}\text { Mean } \\
\text { weight \% }\end{array}$ & $\begin{array}{l}\text { (\%) Frequency } \\
\text { occurrence }\end{array}$ & $\begin{array}{l}\text { Ranking } \\
\text { index }\end{array}$ \\
\hline Fish & 30.35 & 66.7 & 2024.345 \\
Crustaceans & 51.15 & 97.2 & 4971.78 \\
Sand & 11.34 & 38.8 & 439.992 \\
Fish Scale & 7.15 & 30.6 & 218.79 \\
\hline
\end{tabular}

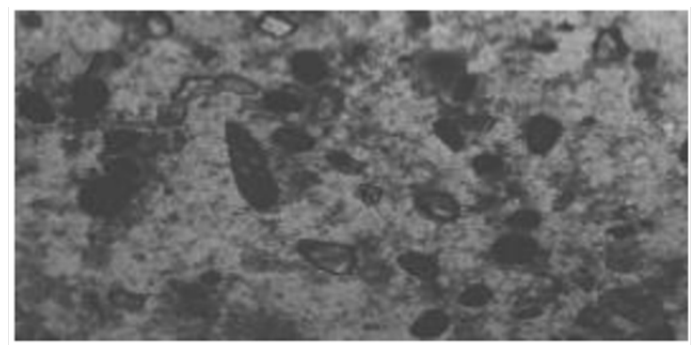

Figure I Sand.

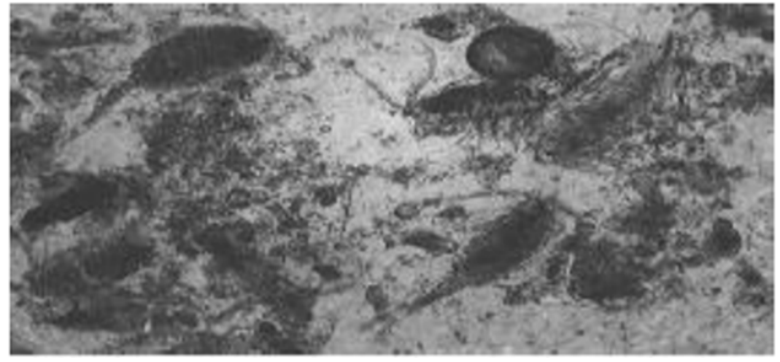

Figure 2 Copepods. 


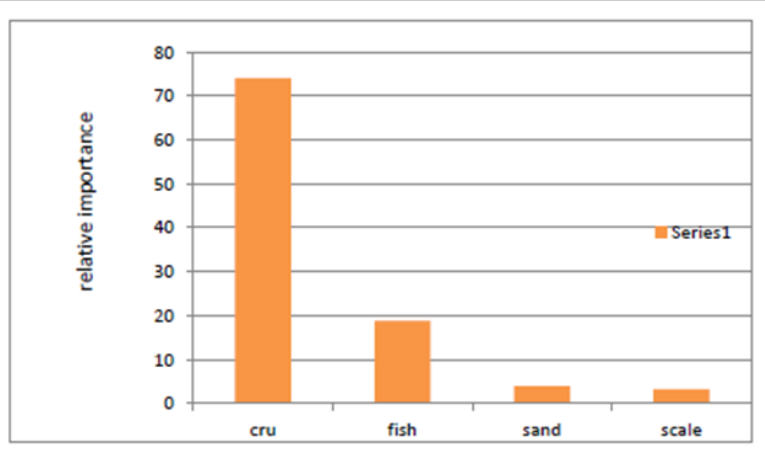

Figure 3 An index of relative importance of prey or index of preponderance shows as those crustaceans ranked first which is about $74 \%$.

The intensity of feeding was assessed visually based on the distension of the stomachs and was classified as empty, $1 / 4$ full, $1 / 2$ full, $3 / 4$ full and full. The empty and $1 / 4$ full stomachs were considered as poorly fed and others as actively fed. The volume of stomach ranged from $0.35 \mathrm{ml}$ to $0.91 \mathrm{ml}$. The weight of food consumed varied from $0.1 \mathrm{~g}$ to $1.2 \mathrm{~g}$. The diversity indices (Shannon) (H') and Pielou evenness (E') indices for $R$. kanagurta represents the maximum $\mathrm{H}^{\prime}$ of a given prey category. It ranges from 0 to $\log \mathrm{N}$ or (4). The value of the Shannon and Pielou evenness indicates dietary specialization and diversification. Shannon diversity index has found 0.45 by volume, this low value shows that $R$. kanagurta's specialized diet not generalized like coral reef fishes accompanied by various prey types dominated by the crustacean. But the diet composition for $R$. kanagurta show even distribution between the different food items ( $E^{\prime}=0.76$ by volume) because it is closer to one which is the highest range. The range is from 0 to 1 and the more closer to one show even distribution of the stomach contents in the stomach.

Analysis of food and feeding of mackerel by previous workers showed that mackerel is a plankton feeder. ${ }^{17-21}$ Small planktonic marine copepods $(<1 \mathrm{~mm}$ in length) plays a major role in the pelagic marine food web, serving as a major grazers of phytoplanktons and as prey for icthyoplanktons and other large pelagic carnivores. ${ }^{22}$ Adult Mackerels have sharp teeth and hunt small crustaceans such as copepods as well as fish, shrimp and squid. ${ }^{23-25}$ The present study also showed that copepod was the major food item in almost all the fishes in spite of the expansion of fishing ground to distant and deeper area compared to earlier periods, when fishing was mainly from inshore area. Identification of the copepod species could not carry out due to the expertise constrain.

Pradhan ${ }^{26}$ reported that Mackerel feed on plankton, phytoplankton and zooplankton, the one or the other dominating at different periods of the year. Therefore it is reported that it is not carnivorous, but are exclusively plankton feeders as fish larvae and vertebrate materials were totally absent in the guts. Pradhan ${ }^{26}$ also observed the occasional presence of some fish eggs in the stomachs examined, but there was no regular preference for fish eggs and it is likely that they constitute the diet when abundant in the plankton. Mackerel is a filter feeder ${ }^{27}$ and normally feeds at the surface. Fish scales and sand without any trace of fish bone were observed in the guts at but it cannot be attributed to their feeding at bottom and the habit of feeding on dead fish as observed by Devanesan \& Chidambaram. ${ }^{28}$

The findings from the present study, $R$. kanagurta feed on pelagic crustaceans including copepods that they found in $97.2 \%$ of the stomach and represented $60.5 \%$ and $51.15 \%$ by volume and weight respectively. Fishes accounted $66.7 \%$ occurrence, $22.42 \%$ by volume and $30.35 \%$ by weight, sand $38.8 \%, 8.6 \%, 11.34 \%$ by occurrence, volume and weight respectively and scales $30.6 \%, 8.41 \%, 7.15 \%$ by occurrence, volume and weight respectively. Therefore sand and fish scale has relatively lower importance. The presence of sand grains and fish scales in mackerel stomach has been reported by Devanesan \& Chidambaram, ${ }^{29}$ Bhimachar \& George (30) and Kutty. ${ }^{19}$ Pradhan $^{26}$ found that mackerel impounded $80-90 \%$ of sand grains in their stomach. According to Kutty, ${ }^{19}$ the presence of sand grains, formaniferans, fish scales and molluscan shell bits noticed in the stomachs of mackerel from Bombay waters suggested that the fish in all probability fed on the bottom ooze in the sea. So also from our result that the appearance of sand substance was grainy texture and for copepods it was brownish.

According to Devanesan \& Chidambaram, ${ }^{29}$ mackerel supplements its diet of planktonic organisms by feeding occasionally on dead and decaying fishes at the bottom and at times, fish scales and sand grains. In the present study also, sand grains were observed in the stomachs of mackerel. Moreover, the stomach contents were dark greenish in color when sand grain was present. Foraminifera's also formed a constituent of gut content whenever sand was observed. All these suggest that the entry of sand into the stomach was not fortuitous, but due to bottom feeding habit of the fish occasionally as indicated by Kutty $^{19}$ as well as Devanesan \& Chidambaram. ${ }^{29}$

According to Luther, ${ }^{31}$ fish and the gritty material noticed in the stomach of mackerel might have gained access into the stomach when the fish was in the bag end portion of the seine nets. In the present observation, it is possible that the fish Bregmaceros sp. found in the stomachs was not an accidental entry but it must have been preyed upon by the mackerel. In some of the stomachs, they were in a partially digested condition. Therefore as pointed out by Kutty, ${ }^{19}$ this prey must also have been selected by sight. This is further fortified by the observation of Bhimachar \& George ${ }^{30}$ who stated that mackerel adopt feeding selectivity and accordingly they divided the plankton into two kinds, edible and non-edible. They found that mackerel avoided non-edible plankton such as salps, medusae, ctenophores, stomatopod larvae, chaetognaths and Noctiluca. Pradhan ${ }^{26}$ was also of the opinion that in mackerel, there is a certain amount of selectivity in feeding.

In the present study the feeding habits of the different size groups indicated differences in their prey preferences agreeing with the observations made by some earlier workers..$^{21,32,33}$ The ontogenetic diet variations indicated in the present study are also supported by the observations of Kapoor et al. ${ }^{34}$ that the length of the alimentary canal is indicative of the food preferences of the fishes with carnivores having the smallest gut length and detritivores the highest and that by Rao \&Rao ${ }^{21}$ who observed differences in the relative length of the alimentary tract of juvenile and adult mackerel and attributed it to differences in their feeding habits. $R$. kanagurta was not diversified in its feeding habit or it is a specialist because the diversity the Shannon Index was valued 0.45 by volume from the range of 0 to 4 , so the lower Shannon index the higher the specialized feeder and vice versa. This result was not, unexpected because, being pelagic shoaling fish and as we know the fish is plankton feeder and a predator. From our result unlike reef fish which are associated with huge number of organisms which serve as prey item inhabiting a diversified feeding habit, $R$. kanagurta is highly specialist pelagic fish. But the stomach contents are evenly distributed in the stomach because the calculated eveness index was closer to 1 which is 0.76 from the range 0 to 1 . The closer to one shows even distribution. 
Even though the sample consists of size range from $13 \mathrm{~cm}$ to 25 $\mathrm{cm}$ of Total Length (TL), includes both juveniles and adults, there is no significant difference is observed in the gut content of both. Kuthalingam ${ }^{35}$ reported that the Mackerel is piscivorous in nature. Devanesan \& Chidambaram ${ }^{29}$ stated that the Indian Mackerel occasionally supplements its planktonic diet by feeding at the bottom on the dead and decaying fishes. In the present study the period of sampling and the sample size is being short, observations could not make any clear demarcation with juvenile and adult food content.

\section{Conclusion}

The present investigation confirms the normal pattern of the planktonic diet and of the plankton feeding habits of the mackerel as has been reported by the earlier workers ${ }^{21,26,30}$ with the difference that the food consumed by the fish living in different waters vary to a certain degree depending upon the exigencies of the environment. According to Devanesan \& Chidambaram ${ }^{29}$ suggested that the Indian mackerel occasionally supplements its planktonic diet by feeding at the bottom on the dead and decaying fishes; since we found, sometimes, fish scales and sand in the mackerel stomach. According to Kuthalingam ${ }^{35}$ the mackerel is piscivorous in its habits; for in their stomachs were found fish. The Indian Mackerel is most abundant in Eritrean Red Sea coast for a short period during summer (February-April). Therefore a prolonged period of study round the year is difficult to conduct to obtain detailed information in the feeding habits. The present study aim to generate a base line data for the feeding habits of Mackerel in the Eritrean Red Sea coast since it plays a major role in Eritrean fisheries and food web in the marine ecosystem.

\section{Acknowledgments}

None.

\section{Conflicts of interest}

None.

\section{References}

1. Cuvier. FAO identification of species, volume 4. 1816

2. Frost WE. On the food relationships of the fish in windermere. Scopus. 1946;13:216-231.

3. Hyslope EJ. Stomach content analysis a review of methods and their application. J fish biol. 1980;17(4):411-429.

4. Pillay TVR. A critique of the methods of study of fishes. $J$ Zool Soc. 1952;4(2):185-200.

5. Natarajan AV, Jhingran AG. Index of Preponderance - a method of grading the food elements in the stomach analysis of fishes. Indian $\mathrm{J}$ Fish. 1961;8(1):54-59.

6. Zanden, vander MJ, Rasmunssen JB. Variation in $\mathrm{N}$ and $\mathrm{C}$ trophic fractionation: Implications for aquatic food web studies. Limnol Oceanogr. 2000;46(8):2061-2066.

7. Seaburg KG. A stomach sampler for live fish. J Fish Biology. 1957;16(4):441-444.

8. Robichaud DA, Wlner RW, Bailey RFJ. Differential selection of crab Chironectes opilio and Hyas spp. as prey by sympatric cod Gadus morhua and thorny skate Raja radiata. Fish Bull. 1991;89(4):669-680.

9. Liao H, Pierce CL, Larscheid JG. Empirical assessment of indices of prey importance in the diets of predacious fish. Trans Am Fish Soc. 2001;130(4):583-591

10. Hovde SC, Albert OT, Nilssen EM. Spatial, seasonal and ontogenetic variation in diet of northeast Arctic Greenland halibut (Reinhardtius hippoglossoides). ICES J Mar Sci. 2002;59:421-437.

11. Griffiths SP, Fry GC, Manson FJ, et al. Feeding dynamics, consumption rates and daily ration of long tail tuna Thunnus tonggolin Australian waters, with emphasis on the consumption of commercially important prawns. Mar Freshw Res. 2007;58(4):376-397.

12. Hanson JM, Chouinard GA. Diet of Atlantic cod in the southern Gulf of St. Lawrence as an index of ecosystem change, 1959-2000. J Fish Biol. 2002;60(4):902-922.

13. Kulbicki M, Bozec YM, Labrosse P, et al. Diet composition of carnivorous fishes from coral reef lagoons of New Caledonia. Aquat Living Resour. 2005;18(3):231-250.

14. Qasim SZ. The dynamics of the food and feeding habits of some marine fishes. Indian J Fish. 1972;19(1\&2):11-21.

15. Collette BB, Nauen CE. FAO Species Catalogue. Vol 2, Scombrids of the World. An annotated and illustrated catalogue of Tunas, Mackerels, bonitos and related species known to date. Rome FAO Fish Synop. 1983;125(2):137.

16. Sivadas M, Bhaskaran MM. Stomach content analysis of the Indian mackerel Rastrelliger kanagurta(Cuvier) from Calicut, Kerala. Indian J fish. 2009;56(2):143-146.

17. Venketaraman G. Studies on the food and feeding relationships of the inshore fishes off Calicut on the Malabar Coast. Indian J Fish. 1960;7(2):275-306.

18. George PC. Our current knowledge on the food and feeding habits of the Indian mackerel Rastrelliger kanagurta (Cuvier). Proceedings of the Symposium on Scombroid fishes. 1952;pp.569-573.

19. Kutty MN. Observations on the Indian mackerel Rastrelliger kanagurta (Cuvier) from the trawl catch along the Bombay Coast. Indian J Fish. 1965;9(2)A:590-603

20. Noble A. The food and feeding habit of the Indian mackerel Rastrelliger kanagurta(Cuvier) at Karwar. Indian J Fish. 1965;9A(2):701-713.

21. Rao KV Narayana, Rao KP. Differences in the food of the young and the adult Indian mackerel, Rastrelliger kanagurta(Cuv.) Nature. 1957; 180:711-712.

22. Jefferson TT. The importance of Small Planktonic Copepods and their Role in Pelagic Marine Food Webs. Zoological Studies. 2004;43(2):255266

23. FAO. LAPE Project Forage Species. Rome. 2008.

24. FAO. Scomber japonicas (Houttuyun, 1782) FAO, Species Fact Sheet. 2012.

25. FAO. Scomber cavalla (Cuvier, 1829) FAO, Species Fact Sheet. 2012.

26. Pradhan LB. Mackerel fishery of Karwar. Indian J Fish 3(1): 141-185. 1956.

27. Hardenberg JDF. A reviews on the current knowledge of Rastrelliger IPFC. Rastrelliger Sub-Committee Session, Penang, Malaysia. 1956.

28. Devanesan DW, Chidambaram K. Common Food Fishes of the Madras State, Government Press, Madras, India, p. 40. 1953.

29. Devanesan DW, Chidambaram K. Common food fishes of the Madras Presidency, Government Press, Madras, India, p. 37. 1948.

30. Bhimachar BS, George PC. Observations on the food and feeding of the Indian mackerel Rastrelliger kanagurta (Cuvier). Proc Indian Acad Sci. 1952;36(3):105-118.

31. Luther G. Observations on the fishery and biology of the Indian mackerel Rastrelliger kanagurta (Cuvier) from Andaman Islands. Indian J Fish. 1973;20(2):425-447. 
32. Chidambaram K. Food of the Indian mackerel Rastrelliger kanagurta(Russell) of the west coast of Madras Presidency. Curr Sci. 1944;13(8):214-215.

33. Rao KVN. Food of the Indian mackerel Rastrelliger kanagurta(Cuvier) taken by drift nets in the Arabian Sea off Vizhinjam, south Kerala. Indian J Fish. 1965;9(2):530-541.
34. Kapoor BGH, Smith IA, Verighina. The alimentary canal and digestion in teleosts. Adv Mar Biol. 1975;13:109-239.

35. Kuthalingam MDK. Observations on the food and feeding habits of the Indian mackerel, Rastrelliger kanagurta (Russell). Zool Soc. 1956;8(2):99-106. 